\title{
MODELLING THE FUTURE OF THE BALTIC ENERGY SYSTEMS: A GREEN SCENARIO
}

\author{
L. Petrichenko*, R. Petrichenko, A. Sauhats, K. Baltputnis, Z. Broka
}

Riga Technical University, Institute of Power Engineering,

12-1 Azenes Street, Riga, LV-1010, LATVIA

*e-mail: lubova.petricenko@rtu.Iv

The electricity sector in Europe and in the world is undergoing rapid and profound changes. There is a sharp increase in the capacity of renewable energy sources, coal and nuclear power plants are being closed and new technologies are being introduced. Especially rapid changes are taking place in the energy systems of the Baltic States. Under these conditions, there is an emerging need for new planning tools particularly for the analysis of the power system properties in a long-term perspective. The main contribution of this article lies in the formulation and solution of optimization problems that arise when planning the development of power systems in the Baltic States. To solve this problem, it is necessary to use models of various power plants and make a number of assumptions, the justification of which requires the following actions: to briefly review the current situation of the production and demand of energy in the Baltic power systems; to conduct an overview of the Baltic interconnections and their development; to make forecasts of energy prices, water inflow, energy production and demand; to set and solve the problems of optimization of power plant operation modes; to demonstrate the possibility and limitations of the developed tools on the basis of real-life and forecast data. In this paper, a case study is performed using the main components of the overall modelling framework being developed. It focuses on the Baltic power systems in 2050 under the conditions of significant expansion in the installed capacity of renewable energy sources (RESs) and diminished fossil fuel power plant activity. The resulting electricity generation mix and trade balance with neighbouring countries is assessed, showing that even with significant RES expansion, the Baltic countries remain net importers and because of the intermittency of RESs, there are hours within the year when the demand cannot be met.

Keywords: Modelling, power system planning, solar energy, the Baltic States, wind energy. 
The efforts of the European society towards increasing power supply efficiency and diminishing the impact on climate change (according to the EU Directive 2018/1999) have brought about significant changes in the generation and distribution of energy: rapid changes are observed in the number of renewable energy sources (RESs), their capacity and their share in the amount of energy produced; the role of combined heat and power plants has increased; country-to-country connections have improved [1]; steam-gas technologies have been developed, which form the basis of constructing high-capacity combined heat and power plants; smart grids, smart measurements and Internet technologies with the possibility of two-sided control have been developed, as well as distributed generation, energy accumulation systems. There have been rapid and significant changes in energy demand, prices, and standards.

A considerable increase in the capacities of wind and solar power plants is expected in Europe and worldwide. According to a report by the Global Wind Energy Council [2], the global share of wind energy has increased more than fiftyfold over the recent twenty years. Also, much attention is devoted to solar power, which is testified to by $200 \mathrm{GW}$ of installed capacity in 2019. This is almost twice as much as the total capacity of wind power installations [3]. According to IEA prognosis [4], the total wind and solar capacity will double, expanding by $1123 \mathrm{GW}$ between 2020 and 2025. Combined wind and solar PV generation is to nearly double to slightly above $4000 \mathrm{TWh}$ over the forecast period.

Considerable changes are taking place in the power industry of the Baltic States.
For example, the power transmission network development plan for the Baltic States till the year 2025 is beginning to be implemented. This plan is mainly concerned with a project for synchronising the Baltic electric power systems with the Continental European Network (CEN) and abandoning synchronisation with the Russian unified electric power system [5]. Thus, this project will ensure greater security of supply to consumers in the Baltic States.

Fundamental changes are planned in the energy supply of transport in industry and households. Its electrification is expected and, accordingly, a sharp increase in electricity consumption is forecast.

A significant factor that characterises the state of the Baltic power system is the planned shutdown of several power plants (PPs). Considering the sustainable development strategy goals of each country, it is planned that most of PPs operating with fossil fuel will be decommissioned by 2030 since they are unable to ensure compliance with the requirements to diminish the emissions of greenhouse gases [6], [7]. The above requirement can be met by reorientation to RESs.

At present, several new RES projects have been implemented in each country [7], [8]. Notwithstanding the rapid increase in the RES capacity and in the amount of electricity produced, the import/export balance of Lithuania and Latvia has been becoming increasingly negative over the recent years [9]. Moreover, it is expected that the consumption of electricity will continue to increase due to the electrification of the transport system, the use of electric power in heat supply, households and the industry [1]. This means that the situation regarding balance may deteriorate even more. In 
order to ensure future import/export balance in the Baltic States, an acceptable balance between the power supply and power consumption, the required level of reliability, stability and sustainability, diminished emissions into the atmosphere, and accessible energy prices, considerable and rapid further changes in the structure of power systems are to be expected. Considering all of the above factors in the development of the power system of the Baltic States, there is a need for the analysis of power system adequacy for several years to come.

It can be said that the society aims at developing the power systems so that they meet various limitations and are optimal from the point of view of achieving the set goals. The above goal makes it necessary to solve an extremely complicated optimization problem since the operation and development of the power system involves a vast number of participants. Their goals do not always coincide, the decisions of the participants are made for uncertain future conditions; the efficiency of the actions of each participant depends on natural factors and the actions of other participants. The plans of the partners are not always known. To support decision-makers, effective instruments are needed that are capable of the following: 1) forecasting of the impacting processes for years ahead; 2) choosing technologies, their parameters and modes. It is the formation and approbation of a decision support tool (DST) that the present article is devoted to.

A large number of different DSTs and models are used for various power system analysis and planning tasks. Comprehensive reviews of such tools are given in articles [10]-[12]. The most publicly available and commonly used ones are the powerful MARKAL and TIMES modelling tools. These DSTs use an objective function, which is formulated as minimisation of the total cost of all generators and consumers, or in some cases maximisation of social welfare. The above instruments are based on the use of a huge linear programming algorithm, due to which they are able to solve problems containing many thousands of decision variables. This is a major advantage. Unfortunately, the method of setting the objective function makes it necessary to solve large-scale problems that include all participants of the electricity market (generators and consumers of a large geographical region). In this case, there are significant difficulties in collecting the necessary input information. In addition, there are limitations determined by the use of linear programming and a deterministic problem statement. These limitations are overcome by using the tool described in [12], which represents a highly adaptable energy system modelling framework, Backbone, and also minimises the total costs of energy supply.

Summarising the information presented in the publications devoted to decision support tools in modelling the development of power systems, we can conclude that there is a large number of ways and models to solve this problem. However, for the needs of the present study the summation of all costs is considered as not the most suitable solution for modelling the development of the Baltic power system. In real life, everyone is looking for their own benefits. Under the energy market conditions, a more appropriate objective for individual participants is the maximisation of their separate expected profits or minimisation of the expected costs. Based on individual preferences, the operating modes of the equipment are selected and bids for the generation and demand of energy in the day-ahead market are formed. Only after that does the market operator identify the equilibrium point of supply and demand, the price of energy and the operating mode of each player. There- 
fore, the solution to the problem of determining the state of the market consists of two stages: 1) formation of participants' proposals; 2) determination of the market equilibrium point. The main contribution of this article lies in the use of these two stages in the formulation and solution of optimization problems that arise when planning the development of the power systems of the Baltic States. To solve this problem, it is necessary to use models of various power plants (hydropower, solar, wind, cogeneration, storage plants) and make a number of assumptions, the justification of which requires the following actions: to briefly review the current situation regarding the production and consumption of energy in the energy systems of the Baltic States; to conduct an overview of Baltic interconnections and their development; to make forecasts of energy prices, water inflow, energy production and consumption; to set and solve the problems of optimization of power plant operation modes; to demonstrate the possibility and limitations of the developed tools on the basis of real-life and forecast data.

The rest of the article is organised as follows: Section 2 describes the energy infrastructure of the Baltic States and their neighbours; Section 3 considers the development plans of Baltic and neighbouring countries' energy systems; Section 4 is devoted to the methodology, models, constraints and the forecast process; Section 5 contains a description of the initial data and assumptions, as well as reflects the results of the calculation of energy balance of the Baltic States in 2050; the last sections are devoted to conclusions and discussion.

\section{THE ENERGY INFRASTRUCTURE OF THE BALTIC STATES AND THEIR NEIGHBOURING COUNTRIES}

The total installed generation capacity of the electric power sources in Latvia is about $3000 \mathrm{MW}$, which is made up by the following: the Daugava Cascade hydropower plants (1558 MW); two Riga combined heat and power plants (1025 MW); natural-gas-operated combined heat and PP of small producers (140 MW); RES electric power plants of small producers (270 MW). The amount of electricity produced from RESs has been steadily growing since 2017.

In Lithuania, the share of RESs in the total electricity generation is $64 \%$. Still the ability to meet the needs with the electricity produced in the country has been very low. In 2019, wind power was the most widely used RES for generating electricity [13]. In order of importance, the next most important RESs are biomass, biogas and solar power. However, notwithstanding the rapid increase in the capacities ensured by RESs, the import/export balance of the Lithuanian electricity trade has been becoming increasingly negative over the recent years [9]. The Lithuanian power transmission system is closely interconnected with the neighbouring power systems. The capacity of the LitPol direct current interconnection between Lithuania and Poland is limited by the capacity of the substation (500 MW). The maximum transmission capacity of the already operating high-voltage direct current NordBalt interconnection with Sweden is $700 \mathrm{MW}$.

Due to the use of oil shale, Estonia has a high degree of energy self-sufficiency [14]. The structure of electricity generation sources shows that the share of RESs 
has considerably increased over the past decade. The Estonian electric power transmission system is well interconnected with the power systems of the neighbouring countries. The interconnection with Finland consists of two direct current cables (Estlink 1 and Estlink 2, the total capacity is $1.05 \mathrm{GW}$ ). In 2018 and 2019, the import and export amounts of Estonia diminished considerably.

There has been no significant upward trend in consumption in Finland over the past fifteen years. However, the importance of wind energy has grown significantly.

In Sweden, the capacity of hydroelectric and nuclear power plants has been virtually constant for more than twenty years, but the capacity of wind farms has grown rapidly.

As for Poland, the bulk of the installed capacity of its power plants is constituted by bituminous coal and brown coal power plants. The amount of electricity generation exceeds the consumption, although this tends to gradually become less considerable [15].

\section{OVERVIEW OF POWER SYSTEM DEVELOPMENT PLANS IN THE BALTIC REGION}

When drawing up the future development scenarios of the Latvian power system, it has to be taken into account that RES development, mainly in the form of wind farms, both onshore and offshore, is already actively taking place in the Baltic Sea region. Development of regional wind farms is also on the list of EU priorities. For instance, Estonia and Latvia's planned 1 GW Gulf of Riga offshore wind farm could be Europe's first cross-border project of its kind and pave the way for future cooperation in large-scale offshore renewable capacity. This Estonian-Latvian offshore wind farm will compete with the Lithuanian 700 MW facility planned for 2028 to become the first one built by the Baltics [16]. The Estonian-Latvian offshore wind farm would have a capacity of up to 1000 MW and it is expected to be completed in 2030 [17]. Latvia and Estonia are actively developing their power transmission networks to make it possible to connect this kind of wind farms to the power transmission grid in the future. For example, it is planned to reconstruct two of the existing Latvian-Estonian interconnections from
Valmiera in the territory of Latvia, increasing the transmission capacity of the lines by 500/600 MW. Also, the 3rd Latvia-Estonia interconnection was completed and commissioned at the end of 2020 [18].

There is one more powerful pilot project in Lithuania, namely, an experimental floating PV (FPV) power plant project at Kruonis pumped storage hydropower plant reservoir. According to initial calculations, the synergy of Kruonis and FPV modules would generate enough electricity to supply more than 120000 households yearly [19].

However, due to environmental requirements, a number of generating units of the Narva PP complex (Estonia) are to be shut down in the nearest years. Thus, by 2023, there is to be a capacity drop by $501 \mathrm{MW}$ and another one of $700 \mathrm{MW}$ - by 2031 [6].

The capacity of the LitPol LithuaniaPoland direct current interconnection is limited by the capacity of the substation (500 MW). It is planned to expand it to $1000 \mathrm{MW}$ and set up one more interconnection with Poland, using an underwater cable in the sea (the Harmony Link project, capacity: $700 \mathrm{MW}$ ) [20]. 
Estonia is planning to achieve RES augmentation not only by developing wind farms and expanding the use of biomass (wood) energy but also by building pumped storage hydropower plants (PSHPPs). At the 500 MW PSHPP planned in Paldiski municipality, the bottom reservoir is to be located deep under the ground. The construction of the plant is to be started in 2022 and it could start operating in 2029 [21].

At the moment, "Eesti Energia" (Estonia) is constructing a number of solar power plants with a total capacity of $7 \mathrm{MW}$ and is planning to increase their capacity by $50 \mathrm{MW}$ by the year 2022 [22]. In the long term (after 2035), Estonia does not rule out the construction of a nuclear power plant so as to replace the capacities lost after shutting down the oil shale power plants. This plant could be located near Narva, which would make it possible to use the existing transmission networks. The capacity under discussion is above $300 \mathrm{MW}$.

Finland is planning to gradually shut down coal-powered combined heat and power plants by 2030 and provide financial support to those power plant operators who will change over to efficient biomass cogeneration and new heating technologies already by 2025 . Upgrade and development of nuclear power generation is planned. It is envisaged to build a power transmission line to Sweden (800 MW) by 2025 .

In Sweden, there is one more planned interconnection: a HVDC line connecting the southern part of Sweden with Germany. The planned capacity is $700 \mathrm{MW}$.

The Polish national energy and climate plan provisions building nuclear power plants in the 2030s, as well as developing wind energy. As regards interconnections, it is important to note the TSOs plan to increase the import/export capacity of the synchronous interconnections with Germany, the Czech Republic and Slovakia by
$2000 \mathrm{MW}$.

Summing up the development plans, let us make the following main conclusions:

1. In the nearest years, a large increase in the capacities of wind and solar power plants is expected. At the same time, a number of power plants in the Baltic States will be shut down so as to diminish the amount of emissions.

2. In most cases, the thermal power plants operate in combined heat and power mode.

3. The Latvian power grid is connected with Lithuania and Estonia and, through them, with the Scandinavian countries, Finland, and Poland; it provides wide but still limited export and import possibilities and operation in the electricity market with a high degree of freedom.

4. For planning and optimising the modes of the power system, forecasts of the impacting processes are needed. The long-term forecasts need to have a time resolution of one hour or finer.

5. Power generation is strongly influenced by weather conditions: outdoor air temperature, precipitation, humidity, water inflow in rivers, wind speed and its direction, solar radiation.

6. The cascade HPPs in Latvia are not suited to seasonal regulation due to the relatively low volume of the water reservoirs. Short-term energy storage is possible at the Daugava HPPs and Kruonis pumped storage power plant.

7. Electrification of transport and households is expected, which is to increase the electricity demand.

8. Sweden, Finland, Poland, Estonia do not rule out the construction of nuclear power plants. These countries are striving to ensure the balance between the generated and consumed energy. No considerable energy exports are expected. 


\section{METHODOLOGY}

\section{A. Solvers of Development Problems and Goals of Problem Solving}

In order to be able to choose the best development alternative, it is necessary to mathematically formulate the development planning problem by describing the optimization goals and considering the technical, economic and legal limitations, as well as the available or planned technologies. The formulation of the problem very much depends on the level of the decision-maker and the exact goals. Problems that are characteristic of various decision-makers are shown in Table 1.

Table 1. Solvers of Development Problems and Problem-Solving Goals

\begin{tabular}{|l|l|}
\hline Government level & $\begin{array}{l}\text { Power system structure? Reliability? Emissions? Import? Export? Revenue? } \\
\text { Tax levels? Support amount? }\end{array}$ \\
\hline Major producers & $\begin{array}{l}\text { Plant profitability? Income/expenses? Reliability? Emissions? } \\
\text { Changes in technologies? }\end{array}$ \\
\hline Grid & $\begin{array}{l}\text { Grid structure? Reliability? Stability? Risks? Losses? Transfer capacities? } \\
\text { Import/export? Congestions? Income/expenses? }\end{array}$ \\
\hline Prosumers & $\begin{array}{l}\text { Technical and economic substantiation for choosing technologies? } \\
\text { Income/expenses? Cost of connection? Household electrification? }\end{array}$ \\
\hline Electric vehicle owners & $\begin{array}{l}\text { Technical and economic substantiation for choosing electric vehicles (EVs)? } \\
\text { Income/expenses? }\end{array}$ \\
\hline $\begin{array}{l}\text { Electric storage } \\
\text { equipment owners }\end{array}$ & $\begin{array}{l}\text { Technical and economic substantiation for choosing energy storage equipment? } \\
\text { Income/expenses? }\end{array}$ \\
\hline
\end{tabular}

Development decision-makers as well as the possible problems vary, yet in most cases it is necessary to evaluate economic indicators, for example, the net present value (NPV) of the cash flow and the

\section{B. The Modelled Power System}

Below, we will look at a united power system whose participant countries set up the Nord Pool [23] electricity market, which is divided into a number of areas. The market participants, on the one hand, compete with one another and strive for maximum profit. On the other hand, exchange of energy and reserves takes place among countries. In order to ensure coordination of the independent energy producers, energy markets of various types have been set up, by means of which a certain order is brought into the overall activity. Under income/expenses of any year. This makes it possible to apply a unified approach and similar algorithms to various problems.

market conditions, fluctuating energy prices are formed. Producers are forced to adapt their energy generation to the fluctuating prices [23]. The operation of energy companies and its characterising factors, for example, the amount of energy generated and fuel consumed, profit, production costs, and others, are changeable and depend on natural factors and the behaviour of other market participants. When choosing the operation mode and the generator capacities and technologies, it has to be taken into account that the amount of energy generated 
must be equal to a fluctuating demand and many technical and legal limitations need to be met. The choice problem can only be solved by planning energy generation for a future time period. Depending on the problem formulation, the length of the planning period can be a matter of seconds, minutes, hours or even decades.

The planning should best be done in the form of an optimization problem, which in turn necessitates the formation of production process models and the description of operation conditions, possibly in the form of models, in future periods. A power system is influenced by many factors and processes. One of the tasks of the present study is the choice of the main influencing processes. Then, the process forecasting method has to be chosen. This choice is impacted, on the one hand, by the physical essence of the process, and on the other hand, by the formulation of the optimization problem used. In addition, the solving of the abovementioned choice tasks strongly depends on the structure and parameters of the power system in question and its producers, as well as the energy market organisation principles. When designing energy facilities or a group of energy facilities, it has to be taken into account that they operate at constantly changing conditions. To perform an analysis of the operation of energy facilities, the following is necessary: mathematical models of impacting processes; power system models; models of the mode control system; models of electricity markets. Below, we will use a modelling platform, a generalised structure of which is provided in Fig. 1.

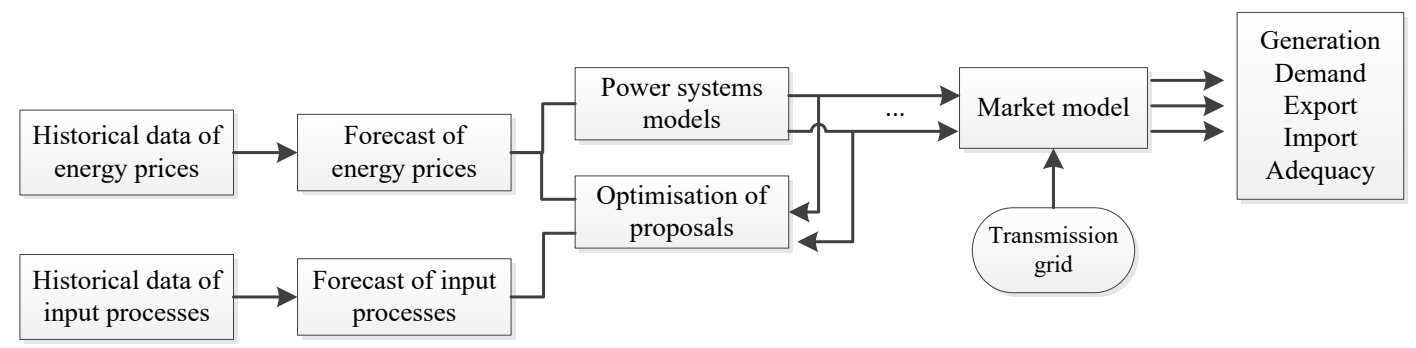

Fig. 1. A generalised structure of the modelling platform.

The power system model forms the core of the structure in question; this core can be embodied in various ways. The exact embodiment determines the requirements regarding the list and description of impacting processes. The structure of the model of the Baltic States power system used in the present study is provided in Fig. 2.

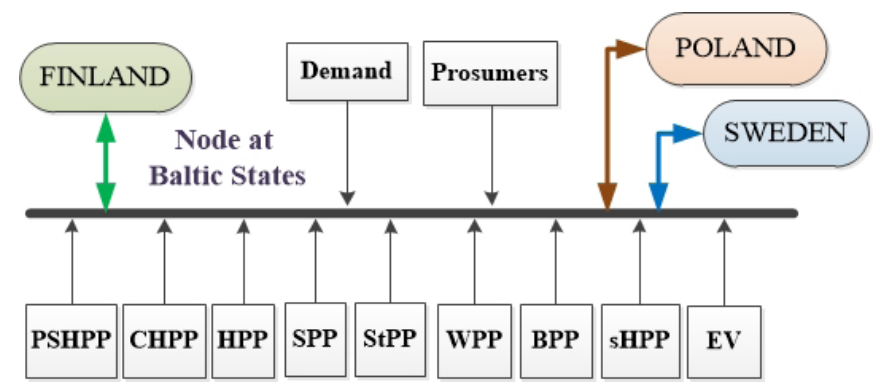

Fig. 2. A diagram of the modelled power system. 
The structure depicted in Fig. 2 includes the following main objects, the list of which corresponds to existing and prospective energy sources: pumped storage hydropower plants (PSHPPs), hydropower plants (HPPs), small HPPs (sHPPs), solar power plants (SPPs), wind power plants (WPPs), storage power plants (StPPs); electric vehicles (EVs); prosumers; electricity demand and interconnections between the Baltic States and Finland, Poland, Sweden. We assume that all of the above objects are connected to one Baltic electricity node. We assume that the shareholders of the plants strive to increase their profitability and are

\section{Forecasting of Processes}

In order to ensure profitability and adequacy of the operation of the power system in the Baltic States, long-term forecasts of the following most influential processes are needed: electricity prices (in all the countries), electricity demand, heat demand, air temperature, water inflow in rivers, solar irradiance, and wind speed. The above processes can be used for simulating the operation of all existing and planned types of power plants. In order to evaluate the profitability of the PPs, recordings of the processes with a resolution of one hour are needed. Considering that the operation is being planned for thirty years ahead and more, it can be said that also the length of the forecast processes needs to be the same. The above-mentioned processes can be divided into two groups:

1. Stationary processes, whose main characterising parameters remain unchanged over time. We will include here all the weather parameters, which means that we do not consider climate change impact.

2. Non-stationary processes, with parameters that change over time (prices, demand, generation capacities). forced to follow the technical and legal constraints established by the rules of the Nord Pool day-ahead electricity market, the government and the grids. The discussed model encompasses Finland, Sweden, Poland and the Baltic States. Still only the Baltic States are modelled in detail, considering the peculiarities of the major power plants and consumers/prosumers, heat demand, and similar factors. The other countries of the region are modelled by considering the limitations imposed by the interconnections, as well as the forecast development of electricity prices in the discussed trade regions.

To simulate processes of the first group, it is possible to use the historical data of process measurements. Simulation of processes from the second group is considerably more complicated. In our study, we have chosen an algorithm based on Fourier transformation, the annual average, the set of harmonics and white noise. A detailed description of this algorithm is provided in one of our earlier publications [24]. When forecasting the future years, the mean component is removed from the historical data and replaced by the mean forecast in the year in question.

The long-term modelling is done with a rolling optimization horizon by using a medium-term optimization sub-model and long-term data sets, i.e., the medium-term calculation (a week or two weeks ahead) is periodically repeated, gradually moving in time towards the future (Fig. 3).

Let us point out that the division of time into weeks is possible in power systems that do not contain long-term energy storage plants. Detailed forecasting algorithms are described in our earlier studies [25], [26]. 


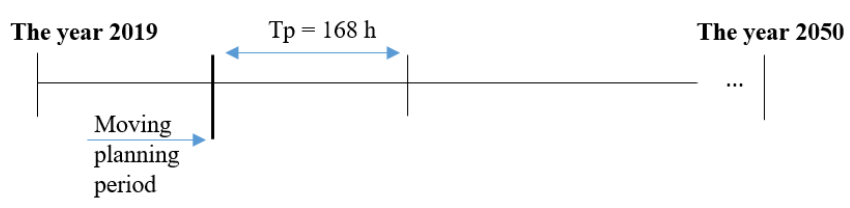

Fig. 3. The temporal structure of forecasting.

\section{Power System Models and Generation/Demand Models}

The formation of the power system generation demand/supply for the day-ahead market takes place by formulating and solving the problem of optimization of the expenses/income of all the participants (see Fig. 2). To simplify this task, the following additional postulates have been assumed:

1. The bids of all the market participants to the market are formed by using the assumption that the hourly energy prices are known (in the form of hourly price forecasts).

2. The modes of the Baltic States power system do not influence the electricity prices in the neighbouring countries.

3. The energy prices of the Baltic States may differ from the forecast ones since they are set in accordance with the market conditions, taking into account not only the supply but also the import/ export possibilities and limitations, as well as the prices of the neighbouring countries.

\section{E. The Electricity Market Model}

Taking into account the above postulates, the hourly price/capacity bid of the Baltic States area for the market of the following days is formed; to this bid, the hourly energy prices (forecasts) of the neighbouring countries are applied; taking into account the limitations of the interconnections, the equilibrium prices of the Baltic States area are determined. In export, power systems with higher prices are prioritised.
4. The internal limitations of the transmission grid in the Baltic States are met in all modes. In this case, the Baltic grid is reduced to one node (see Fig. 3).

5. The power systems of the neighbouring countries are capable of using the interconnections to their full capacity when exporting or importing electricity.

The above postulates make it possible to ensure dramatic simplification of the longterm development planning problem for the following reasons: detailed models of the power systems of the neighbouring countries are not used; the income/expenses of each participant at set future prices depend only on their own actions. The problem of choosing the modes of power plants becomes divided into much simpler subproblems. These can be solved by applying medium-term mode planning models and tools, the substantiation and description of which are addressed in a wide range of scientific literature.

Every hour, the model searches through export/import and Baltic States generation and demand alternatives, looking for generation and demand balance and applying market conditions and thus choosing the cheapest energy generation alternative that ensures balance. Such a model is based only on the checking of elementary logic expressions and inequalities, and is thus easy to implement. 


\section{F. The Tools to be Used}

The structure of the power system model in the Baltic States shown in Fig. 3 encompasses a number of sub-models:

1. Power plants of various types (hydropower plants, among them - the Daugava HPP cascade, combined heat and power plants (based on natural gas, biomass and biogas), thermal power plants, intermittent energy sources wind and solar);

2. Energy storage plants of various kinds (including pumped storage);

3. Consumption/generation models of energy consumers and prosumers that follow on from the forecasting methodology, taking into account the impact of the environment-related factors;

4. Models of transmission power grids; yet at least in the first iterations, the Baltic States are depicted with one node, which has transmission limitations with the neighbouring countries. Tools for solving optimization problems (the socalled solvers).

The set of the tools to be used includes a number of software products synthesised at Riga Technical University:
- Hydropower plant optimization software OptiBidus-HES [27];

- Thermal power plant mode calculation software OptiBidus-TEC;

- Generalized energy storage software [28], which is adaptable to technologies of various kinds, as well as the software specifically intended for Kruonis pumped storage hydropower plant [29];

- Forecasting software products, for example, for water inflow [25] and heat load [26], etc.

The mathematical models embedded into the various tools are combined into a united regional power systems model (RPSM). The RPSM is implemented in the MATLAB programming environment, using, among other things, the optimization problem solvers available there. Data input and output are implemented by using . $x l s x$ files, which can be edited and read, among others, by the widespread Excel application software. For solving the optimization problems, MATLAB solvers are used, more specifically, the linear programming procedure.

\section{CASE STUDY. GREEN SCENARIO}

\section{A. Input Data}

The approach and methodology described above are used for devising longterm development scenarios for the power industry of the Baltic States, with the aim to evaluate the energy generation/consumption balance and the import/export possibilities. Below, we provide a detailed discussion of only one scenario and only for one point in time, i.e., for the year 2050. This scenario is based on the building of highcapacity wind and solar power plants. At the end of the section, a summary of other scenarios is provided.

The developed scenario for 2050 (as an example) includes the following assumptions: 
- The historical data of energy generation by SPPs are taken from a specific facility in Latvia [30];

- The historical data of energy generation by WPPs are taken from the Nord Pool database [23];

- To achieve a specific capacity of the PPs (SPPs and WPPs), the authors calculate and use increase factors;

- The capacity of the LitPol interconnection is $1 \mathrm{GW}$;

- The capacity of the new interconnection (Harmony Link) between Lithuania and Poland is $700 \mathrm{MW}$;
- Other described capacities of existing interconnections in Section 2 are taken into account and remain unchanged;

- The capacities of a Lithuanian gas combined cycle PP (455 MW) and two Latvian natural gas PPs (1025 MW) are kept in reserve and launched only in the case of lack of energy generated from RESs. Hereinafter, they are referred to as gas-fired PPs (GFPPs).

- EVs are not considered in the calculation.

The parameters of the generators for the years 2019 and 2050 are presented in Table 2.

Table 2. Installed Capacity of Baltic Generating RES Facilities

\begin{tabular}{|l|c|c|c|c|c|}
\hline SPP, MW & WPP, MW & HPP, MW & PSHPP, MW & BPP, MW & SHPP, MW \\
\hline \multicolumn{7}{|c|}{ The year 2019 } \\
\hline 88.4 & 1092 & 1558 & 900 & 231 & 67 \\
\hline \multicolumn{7}{|c|}{ The year 2050 } \\
\hline 1000 & 5000 & 1558 & 1400 & 231 & 67 \\
\hline
\end{tabular}

As can be seen from Table 2, it is assumed that by 2050 the increase in the installed capacity of solar energy PP will be $0.91 \mathrm{GW}$, that of wind energy - up to

\section{B. The Forecast for 2050}

We assume that long-term trends in processes (electricity demand and energy prices) can be described by changes in annual average parameters. This assumption makes it possible to use forecasts that have been done for estimating the annual average market price and the annual average demand. We use a long-term forecast provided by SKM Market Predictor. They produce the forecast on the basis of using a version of a commercial modelling system called the EFI multi-area power planning model (EMPS model), also known as Samkjøringsmodellen or the Power Market Analyser [31]. EMPS is a stochastic, market-oriented simulation model for large
3.9 GW, and pumped storage energy - up to $0.5 \mathrm{GW}$. The rest of the RES capacities remain unchanged.

power systems. The model allows simulating large power systems with a relatively high degree of detail, so it is well suited for comprehensive research at the multinational level.

Within the present study, forecasting includes the following steps:

- Initially, the energy price and the electricity demand in each country for 2019 (the base year) are taken from the Nord Pool database;

- Using the Fourier transform, we estimate the constant components and replace them with the predicted average electricity price/demand for 2050 from SKM Market Predictor (Fig. 4). 


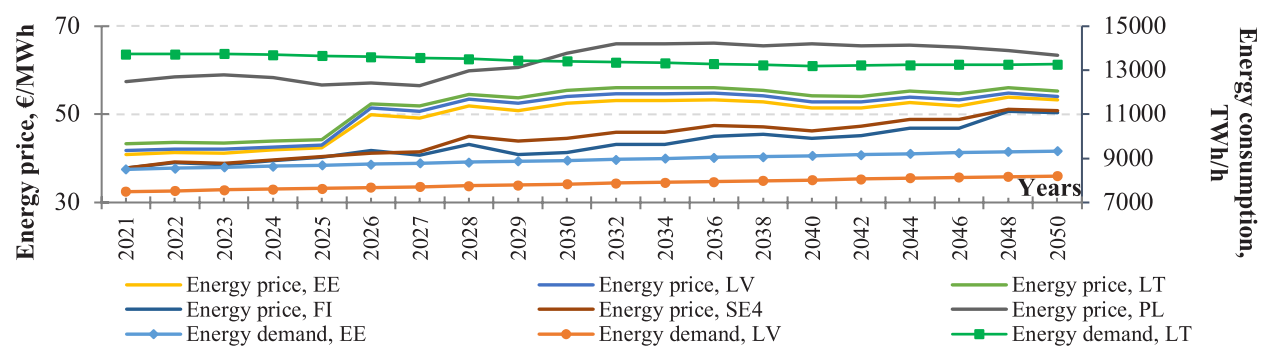

Fig. 4. The annual forecast of energy price and demand by EMPS [31].

Forecast results of the hourly electricity prices of Poland (PL), Sweden (SE4) and
Finland (FI), and the electricity demand of the Baltic States for 2050 are shown in Fig. 5.

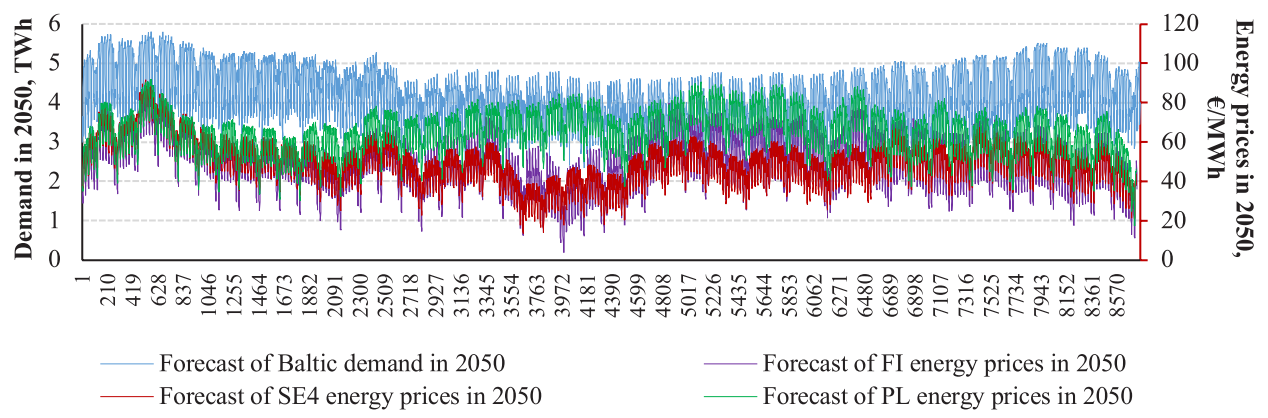

Fig. 5. The forecast of hourly electricity price and electricity demand.

According to Nord Pool data, the total electricity consumption in the Baltic States reached $29.91 \mathrm{TWh} /$ year in 2019. Forecasting and calculating the electricity demand for 2050, this indicator is $36.7 \mathrm{TWh}$. Over 30 years, the estimated increase is $23 \%$. From Fig. 5 it is obviously seen that the highest energy price is recorded in PL. The average value in 2050 is $64.6 € / \mathrm{MWh}$ (by $18.72 \%$ more than in 2019). Lower prices are expected in Sweden (the average value is $48.03 € / \mathrm{MWh})$. In Finland, the average price is expected to rise by $27 \%$ compared to 2019 .

\section{The Balance of the Baltic States in $\mathbf{2 0 5 0}$}

Figure 6 presents the results of energy generation modelling at the Baltic renewable energy PPs in 2050.

In 2050, the Baltic States are modelled to generate a total of 21.34 TWh of electricity from RES power plants. This constitutes $72 \%$ of the required amount of electricity. From Fig. 6 it follows that wind energy is the most-used RES for electricity generation, accounting for $67.3 \%$ of the total amount of generated electricity. The next most important types of RESs are PSHPPs ( $15.23 \%$ of the total electricity generation), SPPs (5.4\%), HPPs ( $8.9 \%)$, BPPs (2.72\%) and sHPPs $(0.4 \%)$.

Despite the large amount of energy produced by RESs, there is not enough energy in the Baltic States to meet the electricity demand (36.7 TWh). As a result, there is a need for electricity import/export, cooperating with neighbouring countries. 


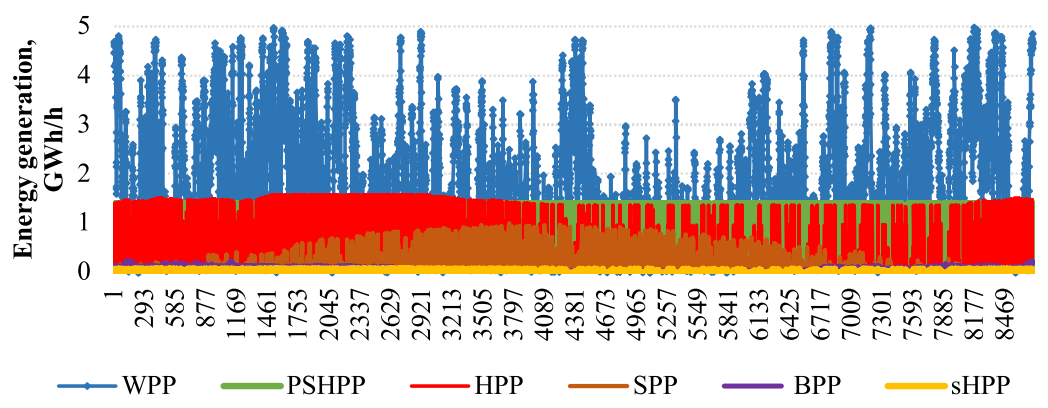

Fig. 6. Energy generation at the Baltic RES PPs.

Figure 7 shows the hourly energy bal- eration) of the Baltic States for 2050. ance (difference between demand and gen-

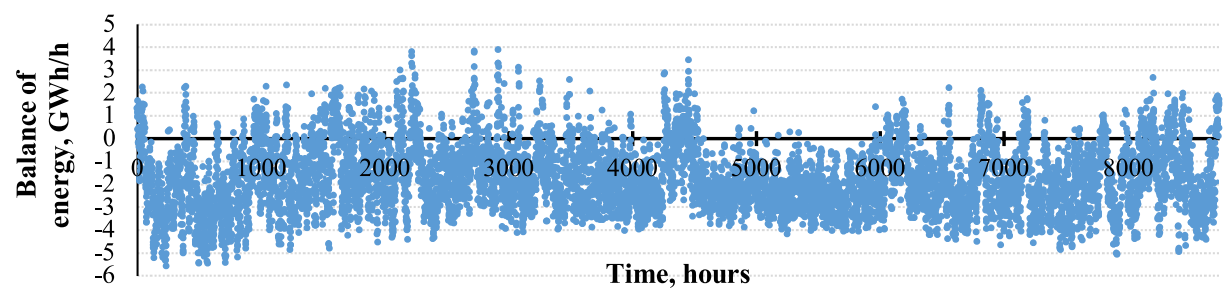

Fig. 7. The energy balance of the Baltic States in 2050.

Analysing Fig. 7, the following conclusions can be drawn: in 1097 cases there is an excess of electricity in the power system, in 7639 cases there is an energy deficit. The maximum value of energy surplus is $3891 \mathrm{MWh}$, whereas that of energy deficit is $-5574 \mathrm{MWh} / \mathrm{h}$. The average value of bal- ance is $-1776 \mathrm{MWh} / \mathrm{h}$.

Considering the capacities of the interconnections and the forecast of energy prices for 2050, the surplus energy could be sold (Fig. 8) to neighbouring countries (Sweden (SE4), Finland (FI), Poland (PL)).

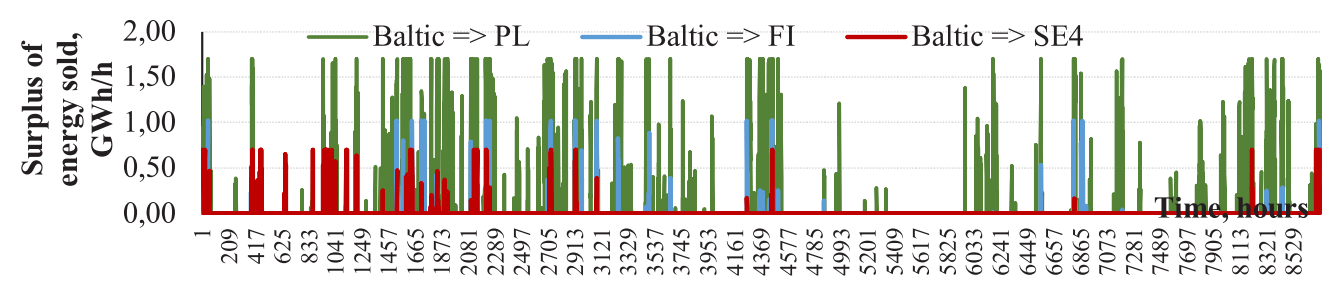

Fig. 8. Surplus of energy sold to FI, SE4, PL.

As shown by the results in Fig. 7, the hourly values of energy surplus or deficit in many cases exceed the capacity of the interconnections between the Baltic States, and one neighbouring country therefore cannot ensure the balance. As a result, hourly export (or import) procedures are carried out between the Baltic States and several countries at the same time, depending on the values of energy prices in the neighbouring countries.

The forecast energy prices are sorted from higher to lower ones. Firstly, the excess energy amount is sold to the country 
with the highest prices, next, with the secondhighest prices and so on. In 107 cases, the excess energy was sold to Sweden, in 106 cases to Finland and in 1018 to Poland. However, in six cases, the surplus energy was not sold due to line transmission capacity limitations. Among the six cases, the maximum value of excess energy is
474.92 MWh/h and the minimum value $13.61 \mathrm{MWh} / \mathrm{h}$.

As regards the energy deficit, it could be addressed by buying energy from neighbouring countries, and if there is still not enough energy, the reserve is used (GFPPs). In Fig. 9, the results of purchasing energy from PL, FI, SE4 are presented.

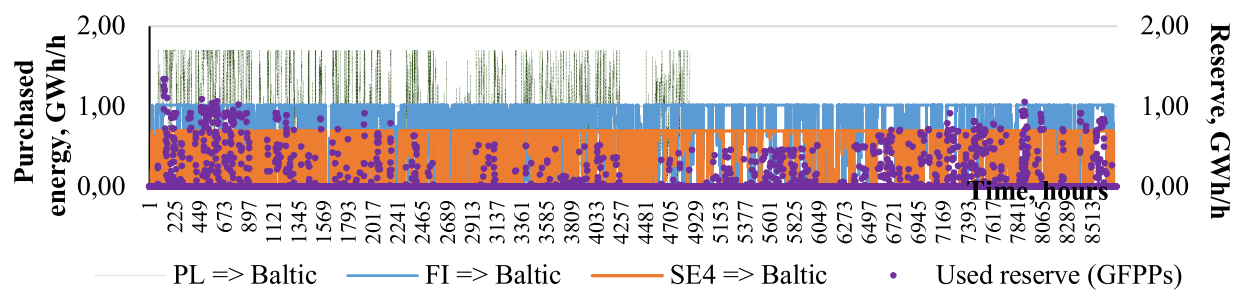

Fig. 9. Energy purchased from FI, SE4, PL (left axis) and GFPP generation (right axis).

The forecast energy prices are sorted from low to high. In 6718 cases, the necessary energy was bought at a low price from Sweden, in 7227 cases from Finland and in 5059 cases from Poland. In 939 cases, the reserve energy from GFPPs was used. However, in 207 cases, the energy deficit was not met. Among 207 cases, the maximum value of deficit energy is $1242 \mathrm{MWh} / \mathrm{h}$ and the minimum value is $0.008 \mathrm{MWh} / \mathrm{h}$.

In Table 3, we present the results of the Baltic energy balance calculations, using different additional scenarios. It should be noted that only the capacities of SPPs and WPPs have been changed.

Table 3. Baltic Energy Balance Results Using Different Scenarios

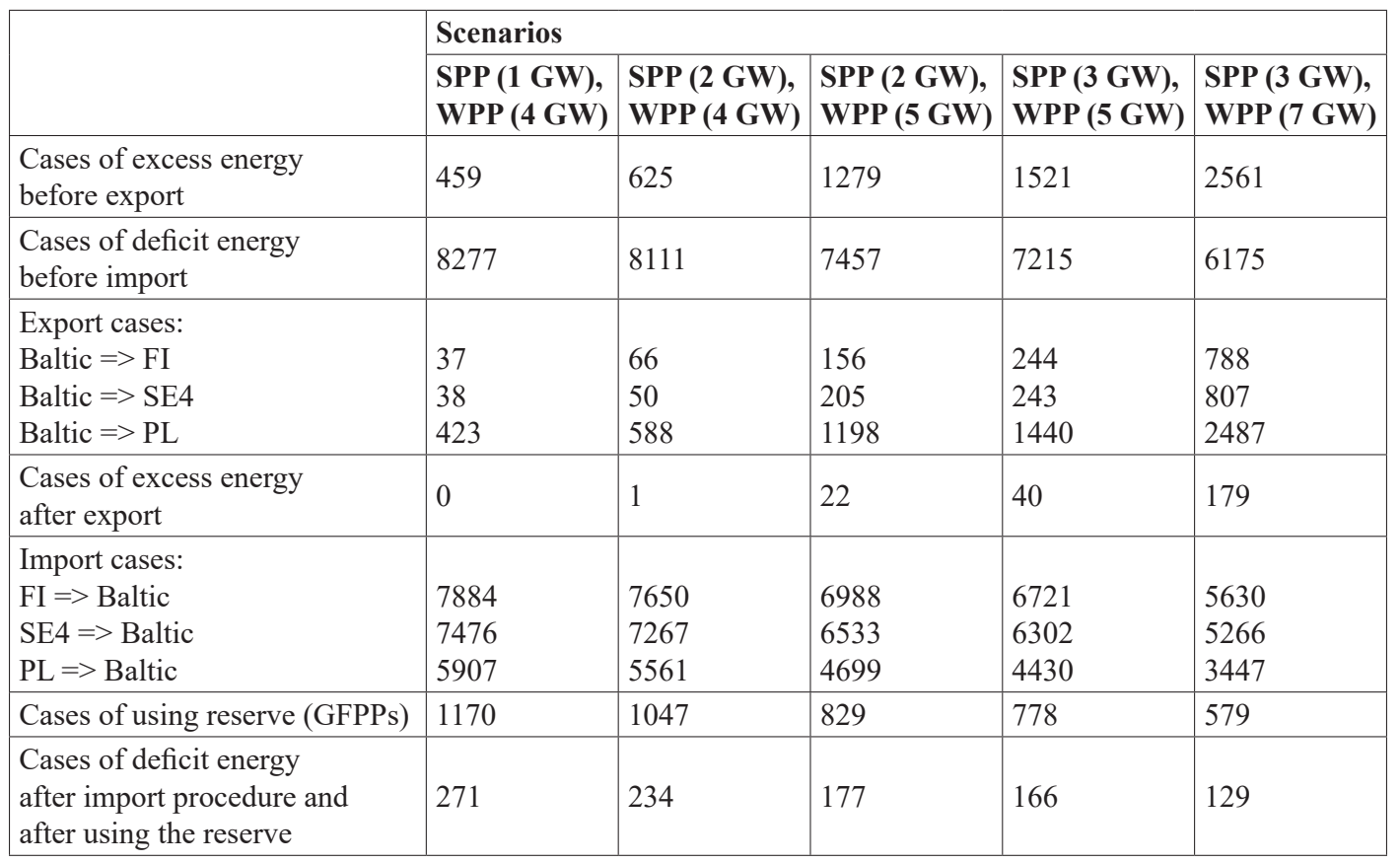


From Table 3, the following conclusions can be drawn: an increase in the capacity of SPPs and WPPs not only offers advantages (meeting most of the electricity demand) but also creates issues in the operation of the power system such as potential excess and deficit of energy. Before export procedures, excess energy cases range from $5.29 \%$ (in the first scenario) to $29.32 \%$ (in the fifth scenario) of the total possible cases. After selling energy to neighbouring countries, the percentage of cases decreases, from $0 \%$ to $2.04 \%$. However, in the case of energy shortages, a different situation emerges. Before import procedures, deficit energy cases range from $-94.75 \%$ (in the first scenario) to $-70.68 \%$ (in the fifth scenario) of the total possible cases. In this situation, the minus sign is used, since we are talk- ing about a lack of energy, thus highlighting this fact. After buying the necessary energy from neighbouring countries and using the reserve from the GFPPs, the percentage of cases increases, and, as a result, energy deficit cases range from $-3.10 \%$ (in the first scenario) to $-1.47 \%$ (in the fifth scenario).

Despite the improvement in the situation after import/export, in several cases the problem of energy surpluses and deficits remains unresolved. Even though the percentage of such cases is small, the highest values of the amount of insufficient or excess energy are large. For example, the maximum excess values in the 2 nd -5 th scenarios are $16.8 \mathrm{MWh} / \mathrm{h}, 1053 \mathrm{MWh} / \mathrm{h}$, $1709.7 \mathrm{MWh} / \mathrm{h}$ and $3500 \mathrm{MWh} / \mathrm{h}$, respectively.

\section{CONCLUSIONS AND DISCUSSION}

1. In the Baltic States, significant changes in energy production and distribution are ongoing: the number, capacity and share of renewable energy sources in the amount of energy produced are growing rapidly; the role of combined heat and power plants has increased; the crossborder connections have improved; steam-gas technologies, distributed generation, and energy storage systems have been developed. The energy demand, prices, and related regulations have changed rapidly and significantly.

2. A significant increase in the capacity of wind farms and solar power plants is expected in the Baltic States. This leads to the need to understand and predict the functioning and performance of individual components of the energy system or the overall behaviour of the system. This motivates the development of optimization models and analysis of the adequacy of the energy system.
3. The choice of the operating mode of a power plant can be made on the basis of the formulation and solution of a complex optimization problem that requires prediction of the processes of price changes, energy generation and demand for a long period and at a high resolution.

4. Long-term electricity price and demand prediction can be implemented based on the use of external predictions of changes in average annual prices and the adoption of a hypothesis about the invariance of seasonal and random components during the planning period.

5. In 2050 modelling results, the Baltic States as a whole experience a shortage of electricity generated from renewable energy sources to meet their electricity needs. In six scenarios, the percentage of electricity generated from electricity demand of the Baltic States varies from $49.56 \%$ to $78.8 \%$. Even after import/ 
export, in several cases the problem of energy surpluses and deficits will remain unresolved.

6. Cooperation between neighbouring countries is of great importance. The Baltic States have well-developed interconnections with Finland, Sweden and Poland. Moreover, until 2050, it is planned to increase the capacity of these lines. This makes it possible to increase the volume of electricity export and import.

7. An important aspect of reliability is the serviceability of power lines. In this article, it is assumed that all the lines are working properly and the criteria (n-1) and (n-2) are not taken into account in the calculations. That will be the subject of future work in improving the calculation of the balance of the power system of the Baltic States.
8. The results of calculations show that there are surpluses and deficits of energy in the power system. The import and export of electricity constitute an integral part of the operation of the system. However, even after the sale and purchase of energy, there are hours left when it is necessary to solve the problem of excess and deficit of energy in other ways. In cases of power shortages, the following solutions can be used: using and adjusting demand response programmes, disconnecting less important consumers, using high-capacity storage systems. In cases of excess electricity, it is possible to curtail generation from some of the power plants.

9. The implementation of RESs in the future depends on the decisions taken by the policy-makers and potential investors.

\section{ACKNOWLEDGEMENTS}

The research has been funded by the Ministry of Economics of the Republic of Latvia, project "Innovative Smart Grid Technologies and their Optimization (INGRIDO)", project No. VPP-EM-INFRA-2018/1-0006 and project "Future-proof Development of the Latvian Power System in an Integrated Europe (FutureProof)", project No. VPPEM-INFRA-2018/1-0005.

The paper has been supported by the
European Regional Development Fund within the activity 1.1.1.2 "Post-doctoral Research Aid" of the Specific Aid Objective 1.1.1 "To increase the research and innovative capacity of scientific institutions of Latvia and the ability to attract external financing, investing in human resources and infrastructure" of the Operational Programme "Growth and Employment" (No.1.1.1.2/VIAA/2/18/317).

\section{REFERENCES}

1. AST. (n.d.). TSO Annual Statement. Available at http://www.ast.lv/lv/content/ parvades-sistemas-operatora-novertejumazinojumi

2. Global Wind Energy Council. (2019). Global Wind Report 2019. Available at https://gwec.net/global-wind-report-2019/
3. International Energy Agency. (n.d.). IEA Report. Available at https://www.iea.org/ reports/world-energy-outlook-2020

4. International Energy Agency. (n.d.). Renewables 2020. Analysis and Forecast to 2025. Available at https://www.iea.org/reports/ renewables-2020/renewable-electricity-2 
5. AST (n.d.). Synchronisation with Europe. Available at https://www.ast.lv/en/projects/ synchronisation-europe

6. Estonian National Development Plan of the Energy Sector until 2030. Available at https://www.mkm.ee/sites/default/files/ ndpes_2030_eng.pdf

7. ISSUU. (n.d.). Security of Supply Report. Extract. Elering 2018. Available at https:// issuu.com/elering/docs/elering_vka_2018_ web_trc_eng_v4

8. GAAS. (n.d.). Estonia's Largest Solar Power Plant Started Operating in Pärnu. Available at https://www.gaas.ee/en/ estonia-s-largest-solar-power-plant-startedoperating-in-parnu/

9. Litgrid. (n.d.). Lithuanian Power System. Available at https://www.litgrid.eu/ index.php/power-system/power-systeminformation/national-electricity-demandand-generation $/ 3523$

10. Jain, H., Rahimi, K., Tbaileh, A., Broadwater, R., Jain, A. K., \& Dilek, M. (2016). Integrated transmission \& distribution system modeling and analysis: Need \& advantages. In IEEE Power and Energy Society General Meeting (PESGM), (pp. 1-5), 17-21 July 2016, Boston, MA, USA.

11. Herbst, A., Toro, F., \& Reitze, F. (2012). Introduction to Energy Systems Modelling. Swiss J Econ Stat., 148, 111-135. 10.1007/ BF03399363.

12. Helistö, N., Kiviluoma, J., Ikäheimo, J., Rasku, T., Rinne, E., O’Dwyer, C. ... \& Flynn, D. (2019). Backbone - An Adaptable Energy Systems Modelling Framework. Energies, 12, 1-34. 10.3390/en12173388.

13. Official Statistics Portal of Lithuania. Available at https://osp.stat.gov.lt

14. IEA. (n.d.). Report of Estonian Energy System. Available at https://webstore.iea. org/download/direct/2869?fileName=Eston ia_2019_Review.pdf

15. Generation and Production in Poland. Available at https://bdl.stat.gov.pl/BDL

16. REVE. (n.d.). Joint Baltic $1 G W$ Offshore Wind Farm Set to Weigh on Prices. Available at https://www.evwind.es/2020/08/27/joint- baltic-1gw-offshore-wind-farm-set-to-weighon-prices/76841

17. The Baltic Course. (2020). Estonia, Latvia Planning to Jointly Develop Offshore Wind Farm. Available at http://www.baltic-course. com/eng/good_for_business/?doc $=157852$

18. AST. (n.d.) Latvia - Estonia Third Interconnection. Available at https://ast.lv/ en/transmission-network-projects/latviaestonia-third-interconnection

19. Marine Energy. (2019). Lithuanian Floating Solar Plant Wins Project Funding. Available at https://marineenergy.biz/2019/02/26/ lithuanian-floating-solar-plant-wins-projectfunding/

20. Elering. (2019). Ten-Year Development Plan of the Estonian Electricity Transmission System. Available at https://elering.ee/sites/ default/files/public/Infokeskus/elering vka_2019_web_final2.pdf

21. Tuuliki. (2019). EU Supports the Estonian Storage Project. Available at https://sunly. ee/eu-supports-the-estonian-pumpedhydro-storage-project-that-is-necessary-forcommissioning-more-renewable-energy-inthe-baltic-states/

22. ERR News. (2018). Eesti Energia Constructing $7 \mathrm{MW}$ of Solar Power Stations in Next Year. Available at https://news.err. ee/867987/eesti-energia-constructing-7mw-of-solar-power-stations-in-next-year

23. Nord Pool Group. (n.d.). Nord Pool Energy Exchange. Available at https://www. nordpoolgroup.com/the-power-market/

24. Petrichenko, L., Broka, Z., Sauhats, A., \& Bezrukovs, D. (2018). Cost-benefit analysis of Li-Ion batteries in a distribution network. In 2018 15th International Conference on the European Energy Market (EEM), (pp. 1-5), 27-29 June 2018, Lodz, Poland. 10.1109/EEM.2018.8469782

25. Sauhats, A., Petričenko, R., Broka, Z., Baltputnis, K., \& Soboḷevskis, D. (2016). ANN-based forecasting of hydropower reservoir inflow. In 2016 57th International Scientific Conference on Power and Electrical Engineering of Riga Technical University (RTUCON 2016), (pp. 267-272), 13-14 October 2016, Riga, Latvia. 
26. Baltputnis, K., Petrichenko, R., \& Sobolevsky, D. (2018). Heating demand forecasting with multiple regression: Model setup and case study. In IEEE 6th Workshop on Advances in Information, Electronic and Electrical Engineering (AIEEE), (pp. 1-5), 8-10 November 2018, Vilnius, Lithuania.

27. Sauhats, A., Petrichenko, R., Baltputnis, K., Broka, Z., \& Varfolomejeva, R. (2016). A multi-objective stochastic approach to hydroelectric power generation scheduling. In Power Systems Computation Conference (PSCC), (pp. 1-7), 20-24 June 2016, Genoa, Italy.

28. Sauhats, A., Coban, H., Baltputnis, K., Broka,Z., Petrichenko, R., \& Varfolomejeva, R. (2016). Optimal Investment and Operational Planning of a Storage Power Plant. International Journal of Hydrogen Energy, 41 (29), 12443-12453.
29. Petrichenko, R., Petrichenko, L., Baltputnis, K., Sauhats, A., Gudzius, S., \& Slivikas, A. (2020). Selection of the initial state and duration of the planning period in the tasks of managing energy storage systems. In 2020 IEEE 61st International Scientific Conference on Power and Electrical Engineering of Riga Technical University (RTUCON 2020), (pp. 1-6), 5-7 November 2020, Riga, Latvia.

30. SolarEdge. (n.d.). Solar Generation Data. Available at https://monitoringpublic. solaredge.com/solaredge-web/p/home/ public?locale $=$ en_US

31. SKM Market Predictor AS. (2019). LongTerm Power Outlook 2019. Available at https://www.skmenergy.com/reports/longterm-power-outlook 